\title{
FAKTOR-FAKTOR YANG MEMPENGARUHI KEIKUTSERTAAN IBU YANG MEMILIKI ANAK UMUR >9 BULAN-5 TAHUN UNTUK IMUNISASI MR (MEASLES RUBELLA) DI PUSKESMAS SENAPELAN PEKANBARU TAHUN 2019
}

\author{
Sri Agnes Lexi ${ }^{1}$, Dedi Afandi ${ }^{2}$, Lita $^{3}$, Oktavia Dewi ${ }^{1}{ }^{1}$ Jasrida Yunita $^{1}$, Nurlisis ${ }^{1}$ \\ ${ }^{1}$ Program Studi Pascasarjana STIKes Hang Tuah Pekanbaru \\ ${ }^{2}$ Fakultas Kedokteran UNRI \\ ${ }^{3}$ Program Studi Keperawatan STIKes Hangtuah Pekanbaru \\ Email : agnes.lexi2016@gmail.com
}

\section{FACTORS AFFECTING THE PARTICIPATION OF MOTHER WHO HAS AN AGE OF CHILDREN> 9 MONTHS-5 YEARS FOR MR IMMUNIZATION (MEASLES RUBELLA) IN SENAPELAN HEALTH CENTER PEKANBARU IN 2019}

\begin{abstract}
The MR (Measles Rubella) immunization program promoted by the government in Pekanbaru City is still low, at $17.13 \%$ of the 95\% target and the Senapelan Puskesmas is the lowest for all Puskesmas in Pekanbaru at 20.1\%. This research is to identify the factors that influence the participation of mothers who have children aged 9 months to 5 years for MR immunization at Senapelan Puskesmas Pekanbaru, quantitative research design with cross sectional approach. The research instrument used was a questionnaire. This research was conducted from February to July 2019. The research sample consisted of 282 respondents using a sampling technique. Data analysis uses Multivariate Analysis. The results found there are 2 of 7 variables related to the participation of mothers who have children aged 9 months to 5 years for MR Imunations, namely the belief and role of health workers. Mothers who have confidence do not want their children to be immunized 27 times more at risk of not participating for immunizations, and mothers who do not get servant promotions from health workers 7 times more risk of not participating for immunizations. It is hoped that the Health Office will promote or increase information related to the impact of children not being immunized by MR on social media, so that people are no longer afraid of being immunized. In addition, the puskesmas is working with community leaders, religious leaders, LSM, stake holders to help convince the public that MR immunization is good for the health of mothers and children.
\end{abstract}

Keywords $\quad$ : Children, Factors, Mother's participation, MR Immunization,

\footnotetext{
Abstrak

Program imunisasi MR (Measles Rubella) yang digalakkan oleh pemerintah di Kota Pekanbaru cakupannya masih rendah yaitu sebanyak $17,13 \%$ dari target $95 \%$ dan Puskesmas Senapelan adalah cakupan terendah untuk seluruh Puskesmas yang ada di Pekanbaru yaitu 20,1\%. Penelitian ini untuk mengidentifikasi faktor- faktor yang mempengaruhi Keikutsertaan ibu yang memiliki Anak umur 9 bulan hingga 5 tahun untuk Imunisasi MR di Puskesmas Senapelan Pekanbaru, desain penelitian kuantitatif dengan pendekatan cross sectional. Instrumen penelitian yang digunakan adalah kuesioner. Penelitian ini dilakukan pada bulan Februari s/d
} 
Juli 2019. Sampel penelitian berjumlah 282 responden menggunakan sampling technique. Analisa data menggunakan Analisis Multivariat. Hasil penelitian didapatkan ada 2 dari 7 variabel yang berhubungan terhadap keikutsertaan ibu yang memiliki anak umur 9 bulan hingga 5 tahun untuk Imunsasi MR yaitu keyakinan dan peran petugas kesehatan. Ibu yang memiliki keyakinan tidak mau anaknya diimunisasi lebih beresiko 27 kali tidak ikut serta untuk imunisasi, dan Ibu yang tidak mendapatakan promosi pelayan dari petugas kesehatan lebih beresiko 7 kali tidak ikut serta untuk imunisasi. Diharapkan kepada Dinas Kesehatan untuk menggalakan atau memperbanyak informasi terkait dampak anak tidak di imunisasi MR di media sosial, agar masyarakat tidak takut lagi untuk diimunisasi. Selain itu pihak puskesmas bekerja sama dengan tokoh masyarakat, tokoh agama, LSM, stake holder, untuk ikut turun mayakinkan masyarakat bahwa imunisasi MR baik untuk kesehatan ibu dan anak.

Kata Kunci : Anak, Faktor- Faktor, Imunisasi MR, keikutsertaan Ibu

\section{PENDAHULUAN}

Penyakit Campak dan rubella kaitannya dengan kesehatan reproduksi adalah merupakan penyakit menular yang disebabkan oleh virus. Campak dan Rubella termasuk dalam penyakit ringan pada anak, tetapi dapat memberikan dampak buruk apabila terjadi pada ibu hamil trimester pertama yaitu keguguran ataupun kecacatan pada bayi sering disebut Congenital Rubella Syndrom (CRS) seperti kelainan jantung dan mata, ketulian dan keterlambatan perkembangan. Data surveilans selama lima tahun terakhir yaitu dari 20132018 menunjukan 70\% kasus rubella terjadi pada kelompok usia <15 tahun. Selain itu berdasarkan studi tentang estimasi beban penyakit CRS di Indonesia pada tahun 2013 diperkirakan terdapat 2.767 kasus CRS, 82/100.000 terjadi pada usia ibu 15-19 tahun dan menurun menjadi 47/100.000 pada usia ibu 40-44 tahun (Depkes RI, 2017). Penyakit campak dan rubella dapat memberikan dampak buruk terhadap kesehatan anak di Indonesia, sehingga pemerintah melaksanakan kampanye vaksinasi MR Vaksin MR (Measles Rubella) memberikan manfaat seperti dapat melindungi anak dari kecacatan dan kematian akibat komplikasi pneumonia, diare, kerusakan otak, ketulian, kebutaan dan penyakit jantung bawaan (Ditjen P2P, 2016).

Vaksin MR merupakan vaksin hidup yang sudah dilemahkan dalam bentu serbuk dan pelarutnya. Vaksin MR diberikan pada anak usia 9 bulan sampai dengan 15 tahun (Ditjen P2P, 2016)..Terdapat beberapa kelompok yang termasuk antivaksin, umumnya mengabaikan pencegahan penyakit dan hanya mengutamakan kuratif. Ada beberapa faktor yang menjadi alasan adanya kelompok antivaksin 
diantaranya persepsi mengenai proses pembuatan vaksin yang mengandung babi dan vaksin tanpa sertifikat halal. Kedua hal tersebut menimbulkan persepsi masyarakat terhadap imunisasi (IDAI, 2017).Data Dinas Kesehatan Kota Pekanbaru yang terdiri dari 21 Puskesmas, menunjukkan bahwa yang terendah untuk cakupan imunisasi MR yaitu Puskesmas Senapelan dengan total cakupan 20,1\% dari 10.726 anak. Hal ini sangat jauh dari target Imunisasi MR sebanyak $95 \%$. (Dinkes Kota Pekanbaru, 2018).

Ibu berperan penting dalam kebutuhan imunisasi anaknya, ada beberapa faktor yang dapat mempengaruhi diantaranya pengetahuan tentang vaksinasi dan pendidikan ibu (Senewe, et al., 2017). Pengetahuan tentang vaksinasi yang baik akan mempengaruhi minat ibu memvaksinasikan anaknya (Gahara, et al., 2015).

Ibu dengan pengetahuan yang tinggi akan memberikan kebutuhan imunisasi kepada anaknya serta memperhatikan waktu yang tepat, begitu juga sebaliknya ibu dengan pengetahuan rendah tidak akan mengetahui imunisasi apa yang seharusnya diberikan pada anaknya
(Triana, 2016). Pendidikan ibu merupakan salah satu proses tingkah laku, semakin tinggi pendidikan maka dalam menentukan tempat pelayanan kesehatan semakin baik, begitu juga sebaliknya dengan pendidikan rendah maka tidak memperdulikan pusat pelayanan kesehatan khususnya dalam mengimunisasikan bayinya dengan tepat (Irawati, 2011).

Penelitian yang dilakukan oleh Dessy di Kelurahan Tegal Sari Mandala III Kecamatan Medan Denai tahun 2010 Analisis Kejadian Campak Pada Anak Balita yaitu pengetahuan ibu, umur, jenis Kelamin, status Gizi, asi eksklusif, Pemberian Imunisasi, pendidikan ibu, pekerjaan ibu. Menurut penelitian Tristan, dkk di Kecamatan Malalayang, Manado tahun 2019 faktor- faktor yang mempengaruhi minat imunisasi Measles Rubella yaitu jenis kelamin anak, umur anak, minat imunisasi MR, agama, umur orang tua, pendidikan orang tua, pengetahuan orang tua, dan urutan kelahiran anak. Imunisasi MR adalah imunisasi untuk anak umur $>9$ bulan 15 tahun, hal ini dikarenakan data surveilans kasus rubella terbanyak di Indonesia adalah usia dibawah 15 tahun sehingga untuk mencapai eliminasi rubella di Indonesia maka kelompok 
usia inilah yang menjadi fokus utama dan harus segera di Imunisasi. Terkait hal tersebut peneliti melakukan peneitian hanya pada anak usia $>9$ bulan hingga 5 tahun saja dikarenakan pada saat umur tersebut anak-anak didampingi ibunya langsung untuk imunisasi ke Posyandu Berdasarkan hal tersebut diatas peneliti merasa tertarik untuk mengetahui Faktor-Faktor yang mempengaruhi keikutsertaan ibu yang memiliki anak umur 9 bulan- 5 tahun untuk Imunisasi MR (Measles Rubella) di Puskesmas Senapelan Pekanbaru.

\section{METODE PENELITIAN}

Penelitian ini adalah penelitian kuantitatif dengan menggunakan observasional analitik. Tujuan penelitian ini yaitu untuk mengetahui faktor-faktor yang mempengaruhi Keikutsertaan Ibu yang Memiliki Anak umur $>9$ bulan- 5 tahun untuk Imunisasi MR (Measles Rubella) di Puskesmas Senapelan Pekanbaru. Desain penelitian ini menggunakan pendekatan cross sectional. Populasi dalam penelitian ini Ibu yang Memiliki Anak umur >9 bulan-5 tahun berjumlah 1057 responden .
Perhitungan besar sampel dengan menggunakan rumus Lemeshow (Riwan dan Akdon, 2010) :

$$
n=\frac{Z_{1-}^{2} \propto_{/ 2} \mathrm{p}(1-p) \mathrm{N}}{d^{2}(N-1)+Z_{1-}^{2} \propto_{/ 2} p(1-p)}
$$

Sampel diperoleh sebanyak 282 Responden. Teknik pengambiln sampel secara dengan Purposive sampling dengan kriteria inklusi dan ekslusi, yaitu :Kriteria Inklusi a) Responden adalah ibu dari anak balita yang berumur $>9$ bulan -5 tahun. b) Responden bersedia berpartisipasi dalam penelitian.c) Ibu bisa membaca dan menulis. Kriteria Ekslusi a) Responden tidak berada ditempat pada saat dilakukannya penelitian.b) Ibu yang tidak berdomisili di Puskesmas Senapelan Pekanbaru.

Variabel Independen adalah umur, pendidikan ibu, keyakinan, pengetahuan, sikap, dukungan keluarga, peran petugas kesehatan . Variabel dependen adalah keikutsertaan ibu. 
Tabel 1 Definisi operasional

\begin{tabular}{|c|c|c|c|c|}
\hline No & Variabel & Definisi Operasional & Skala & Hasil ukur \\
\hline 1. & $\begin{array}{l}\text { Keikutsertaan } \\
\text { Ibu }\end{array}$ & $\begin{array}{l}\text { Keikutsertaaan / partisipasi ibu dalam } \\
\text { mengimunisasikan anak umur }>9 \\
\text { bulan-5 tahun }\end{array}$ & Ordinal & $\begin{aligned} 0= & \text { tidak mengikutsertakan } \\
& \text { jika jawaban tidak } \\
1= & \text { mengikutsertakan jika } \\
& \text { jawaban ya }\end{aligned}$ \\
\hline 1. & $\begin{array}{l}\text { Independen } \\
\text { Umur Ibu }\end{array}$ & $\begin{array}{l}\text { Penggolongam umur responden, } \\
\text { satuan tahun terhotung sejak lahir } \\
\text { sampai dengan pada saat } \\
\text { dilakukannya pengambilan data }\end{array}$ & Ordinal & $\begin{array}{l}0=\text { jika umur ibu }<20 \text { tahun } \\
1=\text { jika umur ibu } \geq 20 \\
\text { tahun } \\
\text { (Depkes, 2009) }\end{array}$ \\
\hline 2. & Pendidikan Ibu & $\begin{array}{l}\text { Pendidikan Formal terakhir yang } \\
\text { pernah dijalani dari pendidikan } \\
\text { terakhir ibu yang ditunjukkan dari } \\
\text { ijazah }\end{array}$ & Ordinal & $\begin{array}{l}0=\text { rendah, jika pendidikan } \\
\text { tamatan SLTP Kebawah } \\
\text { 1= Tinggi, jika pendidikan } \\
\text { tamatan SLTA keatas } \\
\text { (Riskesdas, 2010) }\end{array}$ \\
\hline 3. & Keyakinan & Pendapat ibu tentang Imunisasi MR & Nominal & $\begin{array}{l}0=\text { Imunisasi MR tidak } \\
\text { halal dan tidak mau anak } \\
\text { diimunisasi } \\
1 \text { = anak harus diimunisasi } \\
\text { agar terhindar dari } \\
\text { penyakit campak dan } \\
\text { rubella }\end{array}$ \\
\hline 3. & Pengetahuan & $\begin{array}{l}\text { Segala sesuatu yang diketahui ibu } \\
\text { tentang imunisasi MR }\end{array}$ & Ordinal & $\begin{array}{l}0=\text { rendah }<50 \% \\
1=\text { tinggi } \geq 50 \% \\
(\text { Iskani, 2013) }\end{array}$ \\
\hline 4. & Sikap & $\begin{array}{l}\text { Respon atau reaksi ibu mengenai } \\
\text { Imunisasi MR }\end{array}$ & Ordinal & $\begin{array}{l}0=\text { Negatif }:<50 \% \\
1=\text { Positif }: \geq 50 \% \\
\text { (Sunaryo, 2013) }\end{array}$ \\
\hline 5. & $\begin{array}{l}\text { Dukungan } \\
\text { Keluarga }\end{array}$ & $\begin{array}{l}\text { Dukungan yang diberikan anggota } \\
\text { keluarga terhadap ibu dalam kegiatan } \\
\text { imunisasi MR }\end{array}$ & Ordinal & $\begin{array}{l}0=\text { tidak mendukung: } \\
<50 \% \\
1=\text { mendukung : } \geq 50 \% \\
(\text { Sunaryo, } 2013)\end{array}$ \\
\hline 6. & $\begin{array}{l}\text { Peran petugas } \\
\text { kesehatan }\end{array}$ & $\begin{array}{l}\text { Dorongan, motivasi serta pelayanan } \\
\text { yang diberikan oleh petugas } \\
\text { kesehatan (Bidan. Dokter, Perawat) } \\
\text { kepada ibu }\end{array}$ & Ordinal & $\begin{array}{l}0=\text { tidak aktif }:(0 \%-50 \%) \\
1=\text { aktif }(51-100 \%) \\
(\text { Notoadmodjo, } 2010)\end{array}$ \\
\hline
\end{tabular}

Data yang dikumpulkan adalah data primer dari semua variabel independen dengan memberikan kuesioner. Kuesioner yang digunakan adalah kuesinerr yang dibuat sendiri oleh peneliti dan sudah dialakukan uji Validitas dan Reliabilitas. Pengolahan data menggunakan editing, coding, scoring, dan cleaning. Analisis bivariate dilakukan dengan uji Chi-square dan untuk analisis Multivariat dilakukan dengan uji Regresi logistik ganda. Penelitian ini sudah melalui kaji etik penelitian oleh komisi etik STIKes Hangtuah Pekanbaru, dibuktikan dengan adanya surat kaji etik No. 137/KEPK/STIKesHTP/VI/2019. 


\section{HASIL}

Persentase ibu yang tidak ikut serta sebanyak 163 orang $(57,8 \%)$. Hasil uji bivariat terhadap 7 variabel, terdapat 6 variabel yang berhubungan signifikan dengan keikutsertaan ibu yaitu pendidikan ibu $\quad(\mathrm{POR}=1,624)$, keyakinan $(\mathrm{POR}=24,423)$, pengetahuan $(\mathrm{POR}=1,662), \quad$ sikap $\quad(\mathrm{POR}=1,724)$, dukungan keluarga $(\mathrm{POR}=1,704)$, peran petugas kesehatan $(\mathrm{POR}=1,768)$.

Ibu yang memiliki pendidikan rendah beresiko $1 \mathrm{x}$ tidak ikut serta dari ibu yang memiliki pendidikan tinggi, ibu yang memiliki keyakinan bahwa imunisasi MR tidak halal beresiko 24 kali tidak ikut serta dari ibu yang memiliki keyakinan bahwa imunisasi MR dapat mencegah dari penyakit rcampak dan rubella, ibu yang memiliki pengetahuan rendah beresiko $1 \mathrm{x}$ tidak ikut serta untuk imunisasi daripada ibu yang memiliki pengetahuan tinggi, ibu yang keluarganya tidak mendukung beresiko 1x tidak ikut serta daripada ibu yang keluarganya mendukung, ibu yang tidak mendapatkan dukungan dari petugas kesehatan $1 \mathrm{x}$ tidak ikut serta untuk ikunisasi daripada ibu yang mendapatkan dukungan dari petugas kesehatan.

Hubungan Variabel Independen keikutsertaan ibu terhadap imunisasi MR di Puskesmas Senapelan Pekanbaru Tahun 2019

\begin{tabular}{|c|c|c|c|c|c|c|c|c|}
\hline \multirow{3}{*}{$\begin{array}{c}\text { Variabel Independen } \\
\text { dan Kategori }\end{array}$} & \multicolumn{4}{|c|}{ Keikutsertaan Ibu } & \multicolumn{2}{|c|}{ Jumlah } & \multirow{3}{*}{$\begin{array}{c}p- \\
\text { value }\end{array}$} & \multirow{3}{*}{$\begin{array}{c}\text { POR } \\
(95 \% \\
\text { CI })\end{array}$} \\
\hline & \multicolumn{2}{|c|}{ Tidak aktif } & \multicolumn{2}{|c|}{ Aktif } & \multirow[b]{2}{*}{$\mathbf{n}$} & \multirow[b]{2}{*}{$(\%)$} & & \\
\hline & $\mathbf{n}$ & $(\%)$ & $\mathbf{n}$ & $(\%)$ & & & & \\
\hline Umur ibu & & & & & & & & 1,849 \\
\hline$<20$ tahun & 28 & 70 & 12 & 30 & 40 & 100 & 0,092 & $(0,898-$ \\
\hline$\geq 20$ tahun & 135 & 55,8 & 107 & 44,2 & 242 & 100 & & $3,808)$ \\
\hline Pendidikan Ibu & & & & & & & & 1,624 \\
\hline Rendah & 81 & 64,3 & 45 & 35,7 & 120 & 100 & 0,048 & $(1,004-$ \\
\hline tinggi & 82 & 52,6 & 74 & 47,4 & 162 & 100 & & $2,628)$ \\
\hline Keyakinan & & & & & & & & 24,423 \\
\hline Tidak mau & 152 & 77,9 & 43 & 22,1 & 195 & 100 & 0,000 & $(11,921-$ \\
\hline Harus imunisasi & 11 & 12,6 & 76 & 87,4 & 87 & 100 & & $50,035)$ \\
\hline Pengetahuan & & & & & & & & 1,662 \\
\hline Rendah & 79 & 64,8 & 43 & 35,2 & 122 & 100 & 0,039 & $(1,024-$ \\
\hline Tinggi & 84 & 52,5 & 76 & 47,5 & 160 & 100 & & $2,697)$ \\
\hline Sikap & & & & & & & & 1,724 \\
\hline Negatif & 79 & 65,3 & 42 & 34,7 & 121 & 100 & 0,027 & $(1,061-$ \\
\hline Positif & 84 & 52,5 & 77 & 47,8 & 161 & 100 & & $2,802)$ \\
\hline Dukungan Keluarga & & & & & & & & 1,704 \\
\hline Tidak Mendukung & 80 & 65 & 43 & 35 & 123 & 100 & 0,030 & $(1,050-$ \\
\hline Mendukung & 83 & 52,2 & 76 & 47,8 & 159 & 100 & & $2,764)$ \\
\hline
\end{tabular}




\begin{tabular}{|c|c|c|c|c|c|c|c|c|}
\hline \multirow{3}{*}{$\begin{array}{c}\text { Variabel Independen } \\
\text { dan Kategori }\end{array}$} & \multicolumn{4}{|c|}{ Keikutsertaan Ibu } & \multicolumn{2}{|c|}{ Jumlah } & \multirow{3}{*}{$\begin{array}{c}p- \\
\text { value }\end{array}$} & \multirow{3}{*}{$\begin{array}{c}\text { POR } \\
(95 \% \\
\text { CI })\end{array}$} \\
\hline & \multicolumn{2}{|c|}{ Tidak aktif } & \multicolumn{2}{|c|}{ Aktif } & \multirow[b]{2}{*}{$\mathrm{n}$} & \multirow[b]{2}{*}{$(\%)$} & & \\
\hline & $\mathbf{n}$ & $(\%)$ & $\mathbf{n}$ & $(\%)$ & & & & \\
\hline Peran Petuga Kesehatan & & & & & & & & 1,768 \\
\hline Tidak Aktif & 77 & 65,8 & 40 & 34,2 & 117 & 100 & 0,022 & $(1084-$ \\
\hline Aktif & 86 & 52,1 & 79 & 47,9 & 165 & 100 & & $2,884)$ \\
\hline
\end{tabular}

Hasil uji multivariat melewati 6 pemodelan dan tidak peneliti cantumkan 6 pemodelan tersebut dan hanya dicantumkan pemodelan terakhir sehingga kesimpulan dari 7 variabel terdapat 3 variabel tidak berhubungan yaitu umur, sikap dan dukungan keluarga, variabel confounding ada 2 yaitu pendidikan ibu dan pengetahuan sedangkan variabel yang berhubungan yaitu keyakinan dan peran petugas kesehatan. Tabel dibawah ini adalah tabel pemodelan multivariat akhir :

Tabel 3

Pemodelan Multivariat Akhir

\begin{tabular}{llcccc}
\hline \multirow{2}{*}{ No } & \multirow{2}{*}{ Variabel } & \multirow{2}{*}{ p-value } & \multirow{2}{*}{ POR } & \multicolumn{2}{c}{$(\mathbf{9 5 \%}$ CI) } \\
\cline { 5 - 6 } & & & Lower & Upper \\
\hline 1. & Pendidikan ibu & 0,342 & 0,502 & 0,121 & 2.084 \\
2. & Keyakinan & 0,000 & 27,534 & 13,123 & 57,770 \\
3. & pengetahuan & 0,446 & 0,538 & 0,109 & 2,651 \\
4. & Peran petugas & 0,025 & 7,445 & 1,282 & 43,230 \\
& kesehatan & & & & \\
\hline
\end{tabular}

sehingga didaptkan hasil uji yaitu variabel keyakinan multivariat akhir bahwa ada dua (pvalue=0,000) dan variabel petugas variabel yang berhubungan dengan kesehatan (pvalue=0,025).

keikutsertaan ibu dalam imunisasi MR,

\section{PEMBAHASAN}

\section{Keyakinan}

Imunisasi MR merupakan program yang baru dicanangkan untuk dapat menekan kejadian akibat penyakit campak dan rubella. Pemberian imunisasi MR merupakan yang pertama kali dilakukan dan masih menimbulkan perdebatan di dalam masyarakat. Masih terdapat orang tua yang menolak pemberian imunisasi MR dikarenakan kesadaran orang tua terhadap pentingnya imunisasi bagi anak masih rendah, isu yang beredar bahwa 
imunisasi MR mengandung vaksin yang berbahaya, dan status kehalalan vaksin tidak ada label halal dari MUI sehingga responden berpegang teguh pada keyakinannya jika MR tidak halal walaupun responden tersebut memiliki pendidikan dan pengetahuan yang tinggi, dan meskipun kampanye imunisasi merupakan program wajib dilaksanakan di sekolah dan pos pelayanan kesehatan, masih terdapat sekolah yang belum mewajibkan program kampanye ini (Prabandari dkk, 2018).

Keyakinan berhubungan dengan keikutsertaan ibu dalam imunisasi MR . Keyakinan merupakan domain yang sangat penting untuk terbentuknya tindakan seseorang. Individu cenderung untuk melakukan perilaku sehat apabila dia meyakini bahwa perilaku tersebut bermanfaat untuk menanggulangi suatu penyakit. Ibu yang menolak imunisasi MR merasa bahwa imunisasi tidak bermanfaat bagi kesehatan anaknya karena anaknya sudah memiliki kekebalan tubuh untuk melawan penyakit (Prabandari dkk, 2018).

Saat ini vaksin MR memang belum memiliki sertifikat halal, namun tercantum dalam fatwa MUI No 4/2016 yang mendukung program imunisasi nasional. Secara internasional penerapan vaksinasi di negara islam tidak ada masalah. Vaksin MR digunakan sagat aman dan berkualitas, karena sudah mempunyai izin edar dari BPOM, mendapatkan pra qualifikasi dari badan kesehatan dunia (WHO) dan digunakan sejak tahun 1989 lebih daro 140 negara dan lebih dari 1 miliar dosis (Aisyah, 2014).

Oleh karena itu direkomendasikan kepada tenaga kesehatan Puskesmas, agar maksimal dalam melaksanakan imunisasi yang berkaitan dengan persiapan waktu, tempat pelaksana kegiatan. Antara lain dengan melibatkan tenaga ahli untuk menjadi pemateri di beberapa topik tertentu. Agar apa yang dialami menjadi pengalaman yang baik bagi peserta, sehingga dapat membentuk sikap positif bagi ibu itu sendiri dan juga bagi orang lain yang berbagi pengalaman tentang imunisasi MR. Selain itu juga melibatkan ulama atau tokoh masyarakat dalam pendekatan terhadap masyarakat agar keyakinan masyarakat yang tidak mau diimunisasi dapat berubah.

\section{Peran Petugas Kesehatan}

Peran petugas kesehatan berhubungan sebab akibat dengan keikutsertaan ibu. Variabel pengetahuan 
dan pendidikan ibu menjadi variabel Confounding. Ini berarti hubungan peran petugas kesehatan dengan keikutsertaan ibu di kontrol oleh variabel pengetahuan dan pendidikan ibu. Hasil analisis data didapatkan $58,5 \%$ petugas kesehatan aktif atau melakukan promosi kesehatan terhadap keikutsertaan ibu. Penelitian ini sesuai dengan teori yang dikemukakan oleh Effendi dalam Mulati (2005) yang menyatakan peran adalah tingkah laku yang diharapkan oleh seseorang sesuai dengan kedudukan sistem, dimana dapat dipengaruhi oleh keadaan sosial yang konstan. Peran didasarkan pada preskripsi (ketentuan) dan harapan peran yang menerangkan apa yang individu-individu harus lakukan dalam suatu situasi tertentu agar dapat memenuhi harapan-harapan mereka sendiri atau harapan orang lain menyangkut peran-peran tersebut (Friedman, M, 1998).

Lafond A (2014) dalam jurnal yang berjudul Drivers of routine immunization coverage improvement in Africa: findings from district level- case studies, dengan menggunakan pendekatan grounded theory, menemukan bahwa peningkatan cakupan imunisasi disebabkan oleh peran penting dari strategi pelaksanaan dan keterampilan manajer lokal yang mampu menyesuaikan strategi khusus dengan kebutuhan masyarakat. Oleh karena itu direkomendasikan kepada tenaga kesehatan, agar memberikan dukungan untuk meningkatkan cakupan imunisasi MR, antara lain dengan bekerjasama dan melibatkan kader serta tokoh masyarakat untuk mengingatkan jadwal pelaksanaan imunisasi kepada masyarakat.

\section{Variabel Yang Tidak Berhubungan} Secara Signifikan Dengan

\section{Keikutsertaan ibu dalam Imunisasi MR.}

\section{Umur ibu}

Hasil penelitian yang dilakukan terdapat yang berumur $\geq 20$ tahun sebanyak 85,8\%. Umur ibu tidak berhubungan signifikan dengan keikutsertaan ibu dimana pvalue 0,092 $>0,05$. Hasil penelitian ini sejalan dengan penelitian yang dilakukan oleh (Prabandari, dkk, 2018), yang menyatakan bahwa ibu yang tidak menerima imunisasi MR lebih banyak pada kelompok umur dewasa awal $(\leq 35$ tahun) yaitu sebesar 30,9\% dengan nilai $\mathrm{p}=0,254>0,05$ sehingga menarik kesimpulan bahwa tidak terdapt 
hubungan yang signifikan antara penerimaan imuniasi MR dengan umur ibu. Hal ini selaras dengan penelitian (Prayogo tahun 2009) dimana tidak didapati hubungan yang bermakna antara usia ibu dengan status kelengkapan imunisasi dasar pada anak. Penelitian ini tidak sejalan dengan penelitian (Gita dkk, 2016) menyatakan bahwa terdapat hubungan yang signifikan antar umur ibu dengan perilaku kunjungan ibu keposyandu

Usia yang lebih muda umumnya dapat mencerna informasi tentang imunisasi lebih baik dibanding dengan usia ibu lebih tua. Ibu yang berusia lebih muda dan baru memiliki anak biasanya cenderung untuk memberikan perhatian yang lebih akan kesehatan anaknya, termasuk pemberian imunisasi (Ikawati, 2011) usia merupakan salah sat sifat karakteristik orang yang sangat utama, usia juga mempunyai hubungan yang sangat erat dengan berbagai sifat orang lainnya, dan juga mempunyai hubungan yang erat dengan tempat dan waktu (Rahmawati, 2014). Penolakan yang tinggi disebabkan mayoritas ibu kategori usia dewasa awal merupakan keluarga baru yang sebagian besar sudah tinggal memisah dengan orang tuanya, dan pada masa usia tersebut sering terjadi ketidaksiapan secara psikologis dalam pengambilan keputusan terkait kehidupan keluarga termasuk keputusan untuk melakukan imunisasi. Menurut Green (2005), umur merupakan salah satu faktor sociodemografi yang mempengaruhi perilaku seseorang. Umur berpengaruh terhadap terbentuknya kemampuan, karena kemampuan yang dimiliki oleh seseorang dapat diperoleh melalui pengalaman sehari-hari selain faktor pendidikannya (Ningsih, 2008).

Menurut Wawan (2010) salah satu faktor-faktor yang mempengaruhi pengetahuan adalah umur, pendidikan, pekerjaan dan informasi . Dalam hal ini menurut Huclok (1998) yang di kutip oleh Wawan (2010), semakin cukup umur, tingkat kematangan dan kekuatan seseorang akan lebih matang dalam berfikir dan berkerja. Dari segi kepercayaan masyarakat seseorang yang lebih dewasa dipercaya dari orang yang belum tinggi kedewasaannya.Hal ini sejalan dengan hasil yang telah didapatkan yaitu sebagian besar responden berumur $\geq 20$ tahun dimana pada umur tersebut sudah dikatakan matang. Penolakan yang tinggi disebabkan mayoritas ibu kategori usia dewasa awal merupakan keluarga baru 
yang sebagian besar sudah tinggal memisah dengan orang tuanya, dan pada masa usia tersebut sering terjadi ketidaksiapan secara psikologis dalam pengambilan keputusan terkait kehidupan keluarga termasuk keputusan untuk melakukan imunisasi. Usia ibu yang lebih muda umumnya dapat mencerna informasi tentang imunisasi lebih baik dibanding dengan usia ibu yang lebih tua. Ibu yang berusia lebih muda dan baru memiliki anak biasanya cenderung untuk memberikan perhatian yang lebih akan kesehatan anaknya, termasuk pemberian imunisasi (Ikawati, 2011). Namun pada penelitian ini justru ibu dengan usia lebih tua ( $\geq 20$ tahun) yang banyak ikut serta untuk imunisasi MR. Hal ini juga menjelaskan bahwa usia ibu yang mengalami peningkatan dalam batas tertentu maka dapat meningkatkan pengalaman ibu dalam mengasuh anak, sehingga akan berpengaruh dalam upaya pencegahan dan penanggulangan timbulnya penyakit (Rizqiawan, 2008).

\section{Sikap}

Hasil analisis data $57,1 \%$ ibu yang memiliki sikap positif. Hasil penelitian yang dilakukan, sikap tidak berhubungan signifikan dengan keikutsertaan ibu dimana pvalue 0,937
$>$ 0,05. Hal ini berarti sikap tidak mempengaruhi dalam keikutsetaan ibu yang tidak mau untuk anaknya diimunisasi. Ibu- ibu yang tidak ikut serta imunisasi itu disebabkan karena mereka memiliki keyakinan teguh bahwa imunisasi MR tidak halal dan memiliki efek samping terhadap kesehatan anaknya. Walalupun ibu memiliki sikap positif terhadap imunisasi MR, tapi keyakinannya tetap mengatakan bahwa imunisasi MR tidak bagus, maka dia tetap tidak akan mengimunisasikan anaknya, sehingga dipenelitian ini sikap tidak berhubungan dengan keikutsertaan ibu. Hasil penelitian ini tidak sejalan dengan penelitian Dwi, dkk dimana $\rho$-value $0,027<0,05$ sehingga dapat diartikan terdapat hubungan antara sikap dengan kepatuhan dalam mengikuti imunisasi measles-rubella (MR). Sikap merupakan reaksi atau respon seorang yang masih tertutup terhadap suatu stimulus atau obyek.

Perubahan sikap dipengarui oleh sumber dari pesan, pesan dan pengindraan. Pengetahuan, pikiran, keyakinan, dan emosi memegang peranan penting terhadap penentuan sikap seseorang. Sebagaimana kita ketahui Sikap adalah merupakan reaksi 
atau respons seseorang yang masih tertutup terhadap suatu stimulus atau objek. (Natoatmodjo, 2010).

\section{Dukungan Keluarga}

Hasil penelitian yang dilakukan, dukungan keluarga tidak berhubungan signifikan dengan keikutsertaan ibu dimana pvalue 0,906>0,05. Hasil penelitian ini tidak sejalan dengan penelitian yang dilakukan oleh (Yunita, 2018) tentang hubungan dukungan keluarga terhadap minat keikutsertaan vaksinasi MR di puskesmas Kartasura menunjukkan nilai Pvalue < 0,009 (H0: ditolak) artinya terdapat hubungan dukungan keluarga terhadap minat keikutsertaan vaksinasi MR. Dukungan keluarga adalah dorongan dari sanak saudara yang merupakan unit terkecil dari masyarakat yang terkumpul dan tinggal di suatu tempat dalam satu atap dan saling ketergantungan.

Dukungan keluarga merupakan salah satu faktor penting untuk terwujudnya perilaku sehat. Keluarga yang percaya akan keuntungan pemberian imunisasi bagi bayi dan institusi kesehatan akan mendorong anggota keluarga memanfaatkan fasilitas kesehatan yang ada di lingkungan tempat tinggal seoptimal mungkin. Keluarga yang menyetujui dan mendukung keputusan untuk menghindari anak dari penyakit akan mendorong lengkapnya imunisasi dasar yang diterima bayi. Salah satu kunci keberhasilan imunisasi dasar pada anak adalah adanya dukungan dari keluarga, dukungan ini berupa pemberian informasi kepada ibu tentang imunisasi dasar pada anak, menemani ibu saat pergi ke puskesmas untuk diimunisasi serta membantu ibu merawat bayi selama ibu bekerja (Yeni, R, 2006).

Dalam penelitian ini dukungan keluarga tidak berhubungan dengan keikutsertaan ibu dalam imunsasi MR. Hal ini disebabkan karena keyakinan ibu yang kuat tentang imunisasi MR itu tidak halal dan tidak mau anak untuk diimunisasi. Mereka mendapatkan informasi dari berbagai sumber, baik dari lingkungan maupun media. Sehingga walaupun keluarga sangat mendukung untuk anak diimunisasi tetapi responden tetap tidak akan memberikan imunisasi pada anak.

\section{KESIMPULAN}

Berdasarkan uraian pada bab hasil penelitian dan bab pembahasan, maka dapat disimpulan sebagai berikut :

1. Faktor yang mempengaruhi keikutseran ibu yang memiliki anak 
umur $>9$ bulan hingga 5 tahun untuk imunisasi MR adalah keyakinan dan peran petugas kesehatan.

2. ibu yang tidak ikut serta atau yang tidak aktif dalam imunisasi MR sebanyak 163 responden $(57,8 \%)$

3. keyakinan berhubungan signifikan denga keikutsertaan ibu dalam imunisasi MR Ibu yang memiliki keyakinan tidak mau anaknya diimunisasi lebih beresiko 27 kali tidak ikut serta untuk imunisasi dibandingkan ibu yang memiliki keyakinan anaknya harus diimunisasi.

4. Peran petugas kesehatan berhubungan signifikan dengan keikutsertaan ibu dalam imunisasi MR. Ibu yang tidak mendapatakan promosi pelayan dari petugas kesehatan lebih beresiko 7 kali tidak ikut serta untuk imunisasi dibandingkan ibu yang mendapatkan promosi oelayan dari petugas kesehatan

5. Keyakinan dan peran petugas kesehatan adalah variabel paling dominan berhubungan signifikan dengan keikusertaan ibu dalam imunisasi MR .

6. Umur, dukungan keluarga, dan sikap tidak memiliki hubungan signifikan dengan keikusertaan ibu dalam imunisasi MR

7. Pengetahuan merupakan variabel confounding terhadap peran petugas kesehatan

8. Pendidikan ibu menjadi variabel confounding terhadap variabel pengetahuan dan peran petugas kesehatan.

\section{UCAPAN TERIMA KASIH}

Ucapan terimakasih ditujukan kepada Kepala Dinas Kesehatan Kota Pekanbaru, Tempat Penelitian, Puskesmas Senapelan. Prodi Magister Kesmas STIKes Hangtuah Pekanbaru dan seluruh responden dan keluarga yang membantu dalam penelitian ini.

\section{DAFTAR RUJUKAN}

1. CDC, C. F. D.. Vaksin MMR ( Measles , Mumps, dan Rubella ): yang perlu anda ketahui. Lembar Informasi Vaksin. 2018 h: 1-3

2. Dinas Kesehatan Kota Pekanbaru, Rangkuman data Imunisasi MR Pekanbaru. 2018.

3. Ditjen P2P, K. R . Petunjuk Teknis Kampanye Imunisasi Measles Rubella. 2017.

4. Direktorat Surveilans Dan Karantina Kesehatan Tahun 2017 Direktorat Jenderal Pencegahan Dan Pengendalian Penyakit. 2017.

5. Effendy. Keperawatan Keluarga. Jakarta : EGC. 2005.

6. Firman, F. \& Hermansyah, H. Kesuksesan 
program vaksin rubella di sekolah menurut perspektif stakeholder: studi kasus implementasi program rubella di kabupaten Nias. Berita Kedokteran Masyarakat. 2018

7. Gahara, E,. Saftarina, F. Lisiswanti, R. \&Dewiarti, A. N. Hubungan Tingkat Pengetahuan Ibu dan Status Ekonomi dengan Kelengkapan Imunisasi Wajib Pada Anak usia 0-12 bulan di Puskesmas Sawah. Majority., Volume 4 No 9. 2015.

8. Harmasdiyani. The Influence Of Mother's Characteristics Toward Basic Complete Immunization Non-Compliance For Children Under-Two-Years Vol 3. No 3. 2015.

9. IDAI. Imunisasi Campak-Rubella (MR). tersedia dari http://www.idai.or.id/artikel/klinik/ imuni asi/imunisasi-campak-Rubellamr. 2017. [Accesed : 11 Agustus 2018]

10. Imunisasi, P., \& Rubella, M. Pengaruh lingkungan sosial budaya terhadap tingginya penolakan imunisasi mr. 2018.

11. Kantohe, T. V. M., Rampengan, N. H., \& Mantik, M. F. J. Faktor-faktor yang memengaruhi minat imunisasi Measles Rubella (MR) di kecamatan Malalayang,
Manado. Jurnal Medik Dan Rehabilitasi (JMR). 2019.h: 1-6.

12. Kartasura, D. I. P. Hubungan Informasi Yang Diterima Ibu Dari Media Promosi. Retrieved from https://core.ac.uk/download/pdf/148619170. pdf. 2018.

13. Kemenkes RI. Kampanye imunisasi measles rubella (mr). Petunjuk Teknis Kampanye Imunisasi Measles Rubella (MR). 2018.

14. Mitra. Manajemen \& Analisis Data Kesehatan. (A. A. C, Ed.). Yogyakarta: CV. Andi Offset. 2015.

15. Najah, L. Tingkat Pengetahuan Ibu Tentang Imunisasi Tambahan Mr (Measles Rubella) Pada Balita Di Puskesmas Kotagede I Tingkat Pengetahuan Ibu Tentang Imunisasi Tambahan Mr (Measles Rubella) Pada. Studi, Program Pendidik, Bidan Diploma, Jenjang Kesehatan, Fakultas Ilmu. 2017.

16. Prabandari, G. M., Musthofa, S. B., \& Kusumawati, A. Beberapa Faktor yang Berhubungan dengan Penerimaan Ibu Terhadap Imunisasi Meales Rubella pada Anak SD di Desa Gumpang, Kecamatan Kartasura, Kabupaten Sukoharjo. Jurnal Kesehatan Masyarakat. 2018. h: 573-581. 